\title{
WACANA MOP BAHASA MELAYU PAPUA \\ SEBAGAI ILUSTRASI KONTEKSTUAL DALAM PEMBELAJARAN BAHASA INDONESIA DI PAPUA
}

\author{
Aleda Mawene \\ PBS-FKIP Universitas Cenderawasih/aihinyan@gmail.com
}

\begin{abstract}
ABSTRAK
Mop adalah wacana lelucon yang lazim disampaikan dalam bahasa Melayu Papua. Isinya mengandung asosiasi makna tertentu yang menimbulkan kelucuan serta mengundang tawa pendengarnya. Mop pada umumnya disajikan dalam bentuk verbal dengan memanfaatkan kata, kalimat, dan wacana. Penuturan Mop mencerminkan bentuk praktik penggunaan bahasa secara nyata di masyarakat dan menjadi media interaksi sosial yang mampu menyatukan beragam masyarakat yang berdomisili di Papua. Kajian ini bertujuan menjelaskan pemanfaatan wacana Mop dalam proses penanaman konsep kemahiran berbahasa Indonesia melalui pendekatan pragmatis. Datanya berupa wacana Mop bahasa Melayu Papua yang diperoleh dari Buku Kumpulan Mop dan Harian Cenderawasih Pos. Hasil kajian menunjukkan bahwa wacana Mop bahasa Melayu Papua dapat dimanfaatkan sebagai ilustrasi kontekstual dalam upaya pemahaman konsep bahasa Indonesia. Beberapa wacana Mop berkaitan erat dengan konsep diksi, kalimat, pepatah, dan gaya bahasa dalam bahasa Indonesia. Karena bersifat kontekstual, wacana Mop dianggap mampu mengarahkan pemahaman peserta didik tentang konsep bahasa Indonesia secara efektif dan menyenangkan.
\end{abstract}

Kata kunci: Mop, Melayu Papua, ilustrasi, kontekstual, bahasa Indonesia 


\title{
THE MOP DISCOURSE OF MALAYAN-PAPUAN LANGUAGE \\ AS A CONTEXTUAL ILUSTRATION \\ IN LEARNING BAHASA INDONESIA IN PAPUA
}

\begin{abstract}
Mop is the discourse of joke commonly conveyed in Malayan-Papuan Language. The content contains the associations of certain meanings which is emerging humor also make it a laughingstock to the listeners. Generally, Mop is presented in verbal form by using words, sentences, and texts. Mop speech reflects the practical use of the language in society in real life. Also, it becomes the social interaction media which is able to unite various societies that live in Papua. The objective of this study is to explain the utilization of Mop discourse in the investment process of the proficiency to speak Bahasa Indonesia concept through pragmatically approach. The data are Malayan-Papua Mop text taken from the "Buku Kumpulan Mop" (Mop Collections Book-red) and Cendrawasih Pos newspapers. The result of the study shows that the mop discourse of MalayanPapuan language can be used as the contextual illustrations in the efforts of understanding the Bahasa Indonesia concept. Some of the mop discourses are closely related with the concept of diction, sentence, aphorism, and language style of Bahasa Indonesia. Because having contextual characteristic, Mop discourse is considered able to direct the learners' understanding about the concept of Bahasa Indonesia effectively and fun.
\end{abstract}

Key words: Mop, Malayan-Papuan, illustration, contextual, Bahasa Indonesia

\section{PENDAHULUAN}

Pembelajaran kontekstual adalah konsep belajar yang mengaitkan isi pembelajaran dengan konteks kehidupan sehari-hari siswa, baik dari konteks pribadi, sosial, maupun kultural. Konsep belajar ini membutuhkan guru yang dapat memahami latar belakang sosial budaya siswanya. Pemahaman terhadap konteks kehidupan siswa memudahkan guru untuk mengaitkan materi yang dipelajari dengan pola pikir dan gaya belajar siswanya. Dengan demikian, materi yang dipelajari lebih bermakna bagi kehidupan siswa.

Bahasa Melayu Papua merupakan salah satu variasi bahasa Indonesia yang telah lingua franca di Papua. Bahasa ini menjadi bahasa utama dalam komunikasi antaretnis yang berdomisili di Papua. Papua merupakan profil mikro-Indonesia karena di daerah ini menetap berbagai suku dari seluruh penjuru Indonesia. Keragaman suku dan budaya ini memungkinkan bahasa Indonesia, terutama 
Melayu Papua berkembang dengan pesat. Bahasa tersebut merupakan satusatunya alat komunikasi yang paling efektif dalam menjembatani beragam bahasa, suku, dan budaya yang ada di Papua. Bahasa Melayu Papua biasanya digunakan pada situasi-situasi nonformal, sedangkan pada situasi formal digunakan bahasa Indonesia.

Berkaitan dengan itu, penuturan Mop merupakan salah satu peristiwa bahasa yang mampu menjembatani keragaman budaya di Papua. Mop adalah wacana lelucon yang disampaikan dalam bahasa Melayu Papua. Mop berasal dari bahasa Belanda yang artinya lelucon. Danandjaya (2002:118) membedakan lelucon dari humor. Menurutnya, sasaran lecucon adalah orang atau kolektif lain, sedangkan sasaran humor adalah pribadi atau kolektif si pembawa cerita. Konsep ini sejalan dengan praktik penuturan Mop, yakni si penutur cenderung menceritakan kebiasaan orang lain atau kolektif lain daripada dirinya sendiri. Dalam perkembangannya, Mop dikenal dengan nama Mob sebagai akronim dari Menipu Orang Banyak. Mop mengandung asosiasi makna tertentu yang menimbulkan kelucuan dan mengundang tawa dan senyum pendengarnya. Pada umumnya Mop disajikan dalam bentuk verbal dengan memanfaatkan kata, kalimat, dan wacana. Kelucuan yang ditimbulkan oleh Mop tampak pada pengucapan kata dan kalimat bahasa Melayu Papua yang khas dan ekspresi si penceritanya. Dengan demikian, bahasa Melayu Papua merupakan ciri khusus yang melekat pada wacana Mop.

Mop dituturkan pada kesempatan-kesempatan nonformal maupun formal. Masyarakat senang mendengarkan tuturan Mop ketika melepaskan lelah sehabis bekerja, dalam acara-acara santai keluarga atau paguyuban, dan panggung hiburan rakyat. Pada kegiatan-kegiatan resmi pun Mop sering dituturkan sebagai peluruh kekakuan. Akhir-akhir ini, Mop dijadikan sebagai salah satu matalomba dalam kegiatan memperingati Hari Proklamasi Kemerdekaan RI atau hari raya nasional lainnya.

Mop sangat populer di semua kalangan dan kelompok umur, mulai dari anak-anak sampai orang dewasa; dari rakyat jelata sampai pejabat pemerintah. Penuturannya tidak hanya terbatas oleh orang dewasa semata, tetapi juga oleh anak-anak. Penduduk Papua atau setidaknya mereka yang pernah menetap di 
Papua, sudah pasti mengenal dan mengapresiasi Mop sebagai wacana sosial yang membumi.

Paparan tersebut menunjukkan bahwa Mop dapat dimanfaatkan sebagai ilustrasi kontekstual dalam pembelajaran di Papua. Pada umumnya para siswa di Papua sangat familiar dengan Mop. Jika demikian, Mop dapat menjadi alternatif ilustrasi yang cocok bagi penanaman konsep ilmu, seperti bahasa, matematika, dan kewarganegaraan. Pengajaran dengan selingan Mop yang relevan dapat membantu menghilangkan kebosanan siswa, sekaligus memudahkan siswa memahami konsep yang dipelajari. Hal ini sejalan dengan pandangan para pakar bahwa penggunaan humor secara efisien dalam pembelajaran berpengaruh positif bagi kondisi belajar siswa (Purwo dalam Iwong, 2012). Gauter (dalam Rahmanadji, 2007) menyatakan bahwa humor dapat digunakan sebagai sarana persuasi untuk mempermudah masuknya informasi yang ingin disampaikan sebagai sesuatu yang serius dan formal. Dengan demikian, guru dapat berkreasi menghimpun atau mencipta wacana Mop yang relevan dengan isi pembelajaran sehingga proses belajar-mengajar menjadi lebih bermakna dan menarik.

Dari kajian awal ditemukan beberapa wacana Mop Bahasa Melayu Papua (selanjutnya disingkat MBMP) yang berkaitan erat dengan konsep atau prinsip ilmu bahasa, sastra, dan kemahiran berbahasa. Konsep tersebut jika diajarkan kepada siswa terasa membosankan karena terkesan teoritis, misalnya syarat-syarat pemilihan kata (diksi). Pengalaman menunjukkan bahwa meskipun disampaikan dalam bahasa Melayu Papua, Mop dapat membantu siswa dalam mempelajari konsep bahasa Indonesia. Jadi, Mop yang relevan dapat dimanfaatkan untuk menjelaskan konsep fungsi bahasa, diksi, kalimat, peribahasa, dan gaya bahasa.

Berdasarkan masalah yang telah dipaparkan, penelitian ini dilakukan dengan tujuan:

1) mengidentifikasi aspek-aspek kebahasaan yang terkandung dalam wacana MBMP;

2) mendeskripsikan tafsiran konteks wacana MBMP berkaitan dengan kompetensi berbahasa Indonesia;

3) mendeskripsikan manfaat wacana MBMP sebagai ilustrasi kontekstual dalam perkuliahan bahasa Indonesia di Papua. 
Penelitian ini menggunakan metode deskripstip kualitatif untuk menjelaskan pemanfaatan MBMP sebagai ilustrasi kontekstual dalam pembelajaran bahasa Indonesia di Papua. Wacana MBMP dianggap sebagai sebuah fenomena budaya dalam interaksi sosial di Papua yang dapat diamati dan dijelaskan eksistensinya. Secara linguistik, MBMP menggunakan variasi kode bahasa Indonesia yang telah mengalami pidginisasi. Namun, pada tataran praktis, MBMP menjadi media ilustrasi kontekstual bagi guru untuk menjelaskan konsep bahasa Indonesia. Oleh sebab itu, kajian ini diharapkan dapat menggali eksistensi wacana MBMP dan sumbangsihnya bagi pembelajaran bahasa Indonesia di Papua.

Kajian ini menggunakan pendekatan pragmatis dan analisis isi sebagai pisau bedahnya. Secara pragmatis, wacana MBMP memberikan dampak positif dalam pembelajaran pada umumnya dan pembelajaran bahasa Indonesia secara khusus. Ini berarti kajian terhadap wacana MBMP perlu mempertimbangkan konteks penuturannya. Konteks diartikan sebagai situasi yang ada hubungannya dengan ujaran atau kejadian. Menurut Guy Cook (1994:25-25) konteks berkaitan dengan semua situasi di luar teks dan mempengaruhi pemakaian bahasa, seperti partisipan, bahasa, dan fungsi yang diacu. Ditegaskan bahwa studi tentang bahasa selalu dikaitkan dengan konteks karena bahasa selalu berada dalam konteks dan tidak ada tindakan komunikasi tanpa partisipan, interteks, situasi, dan sebagainya.

Partisipan dalam konteks penelitian ini yaitu mahasiswa dan dosen. Pembatasan ini dibuat mengingat wacana MBMP yang diperoleh lebih mengacu pada partisipan dewasa di atas 17 tahun. Tuturan MBMP yang relevan dengan topik dan konsep pembelajaran berdampak ganda bagi mahasiswa. Pertama, bermanfaat bagi penanaman konsep. Kedua, berguna bagi pembentukan sikap atau karakter mahasiswa. Ketiga, menciptakan suasana belajar (perkuliahan) yang menyenangkan. Wacana MBMP yang dipilih secara selektif oleh pengajar akan menimbulkan resepsi positif mahasiswa terhadap isi MBMP dan berdampak pada ketiga hal di atas.

Sehubungan dengan itu, diperlukan analisis yang cermat terhadap isi teks MBMP. Menurut Vrendrenbreght, analisis isi (content analysis) berkaitan dengan isi komunikasi yang meliputi tiga komponen, yaitu siapa yang berbicara, 
apa yang dibicarakan, dan efek apa yang diakibatkannya (Kutha Ratna, 2010:358). Analisis isi dalam kajian ini lebih fokus pada komponen kedua, yakni isi wacana MBMP. Tujuannya untuk mendeskripsikan karakteristik pesan dari sebuah Mop (describing the characteristic of Mop). Holsti (dalam Eriyanto, 2011:32) menegaskan bahwa deskripsi isi suatu pesan dipakai untuk menjawab pertanyaan "what, to whom, dan how" dari suatu proses komunikasi.

Data kajian ini berupa wacana MBMP sebanyak 20 teks. Data tersebut diidentifikasi berdasarkan prinsip analisis isi, yakni terbagi menjadi unit sampel, unit pencatatan, dan unit konteks (Eriyanto, 2011:61). Unit sampel (sampling units) ialah bagian dari objek yang dipilih untuk didalami, yakni wacana MBMP yang berkaitan dengan konsep atau prinsip bahasa, sastra, kemahiran berbahasa, seperti diksi, kalimat, pepatah, dan gaya bahasa. Unit pencatatan (recording units) adalah bagian atau aspek dari isi yang menjadi dasar dalam pencatatan dan analisis Mop. Dalam hal ini kata-kata atau kalimat kutipan teks MBMP yang berkaitan dengan konsep atau prinsip fungsi bahasa, diksi, kalimat, pepatah, dan gaya bahasa. Selanjutnya, unit konteks (context units) ialah konteks yang diberikan oleh peneliti untuk memahami atau mengartikan kata atau kalimat yang berkaitan dengan konsep atau prinsip fungsi bahasa, diksi, konteks kalimat, pepatah, dan gaya bahasa.

Data diperoleh dari tuturan MBMP pada kegiatan-kegiatan nonformal, Buku Kumpulan Mob Melayu Papua oleh Hugo Warami (2009), dan Harian Cenderawasih Pos (2015). Data tersebut dikumpulkan melalui teknik observasi dan studi dokumentasi. Data yang diperoleh selanjutnya dianalisis dengan model Milles dan Huberman (1990), yakni melalui tahap mengumpulkan data, mereduksi data, menyajikan data, menganalisis data, dan menyimpulkan temuan penelitian. Data dianalisis berdasarkan interpretasi konteks dan manfaatnya terhadap proses dan hasil belajar bahasa Indonesia. Oleh sebab itu, analisis berpatokan pada teori yang berkaitan dengan konsep atau prinsip diksi, kalimat, pepatah, dan gaya bahasa. 


\section{PEMBAHASAN}

Hasil kajian menunjukkan bahwa wacana MBMP berkaitan dengan konsep atau prinsip fungsi bahasa, diksi, kalimat, pepatah, dan gaya bahasa. Agar lebih jelas, berikut ini dikemukakan wacana MBMP, tafsiran konteksnya, dan manfaatnya sebagai ilustrasi kontekstual bagi mahasiswa dalam perkuliahan bahasa Indonesia. Karena keterbatasan ruang, dikemukakan kajian terhadap beberapa wacana MBMP sebagai contoh. Relevansi konsep bahasa Indonesia cenderung diarahkan pada pembelajaran Bahasa Indonesia Umum di perguruan tinggi.

\subsection{Wacana MBMP yang Berkaitan dengan Fungsi Bahasa dalam Komunikasi}

Salah satu topik yang dibahas pada pertemuan-pertemuan awal perkuliahan Bahasa Indonesia Umum yaitu kedudukan dan fungsi bahasa Indonesia sebagai bahasa nasional dan bahasa negara. Sebagai bahasa nasional, bahasa Indonesia digunakan sebagai bahasa pemersatu antarsuku yang ada di Indonesia. Untuk membuktikan peranan bahasa Indonesia itu, dikemukakan wacana MBMP berikut ini.

\subsubsection{Wacana Pelan To (Ojo Kesusu)}

Ada sepasang muda-mudi yang sedang jatuh cinta. Yang laki-laki berasal dari Manado dan yang gadis dari Jawa. Dorang dua baru tiba dari kampung jadi masih suka pake bahasa daerahnya sendiri-sendiri. Trus satu kali pace Manado de ajak de pu pacar nonton di bioskop.

Filem yang dong dua nonton bikin suasana tambah romantis. Trus pace de pu tangan mulai bajalan sendiri dan mendarat di de pu pacar pu paha. Anak perempuan tu de rasa gelisah sebab pace mulai tambah smangat ini. Trus dengan halus dia tegur pace.

Gadis : Ojo kesusu to, Mas?

Eee .. langsung saja pace de hajar rem tangan ke sasaran sudah, mo..

Pelan, to.. pace???

Wacana MBMP (01) ini dapat dipakai sebagai ilustrasi bahwa dalam peristiwa komunikasi diperlukan kesamaan kode (bahasa). Ketidaksamaan kode bahasa dapat menyebabkan salah tafsir dari para partisipan. Tuturan si gadis "Ojo kesusu" (bahasa Jawa) bermakna tidak usah terburu-buru (ojo = jangan, kesusu $=$ terburu-buru). Namun, oleh si pemuda kalimat itu ditafsirkan sebagai 
“Ojo ke susu”. Dalam bahasa Jawa kesusu merupakan satu morfem. Pemisahan ke dari susu menyebabkan perubahan makna kata tersebut. Interpretasi si Pemuda Ojo ke susu (bahasa Menado), 'ojo' berarti meremas, misalnya meremas adonan roti hingga kalis, 'ke susu' bermakna ke payudara. Penggunaan simbol atau kode yang berbeda dalam interaksi kedua sejoli ini membuat si pemuda berlaku tidak sesuai dengan permintaan si gadis.

Ilustrasi di atas dapat digunakan sebagai fakta bahwa dibutuhkan sebuah bahasa yang dapat mempersatukan masyarakat yang pluralis. Dalam konteks Indonesia, konsep Bhinneka Tunggal Ika dapat diwujudnyatakan dengan penggunaan bahasa Indonesia sebagai alat pemersatu. Mop ini mengingatkan mahasiswa bahwa mereka tidak perlu khawatir untuk berkarya di pelosok Nusantara karena memiliki bahasa Indonesia sebagai sarana komunikasi yang efektif. Namun, disarankan juga untuk tetap memelihara bahasa daerah sebagai khasanah budaya bangsa yang menunjukkan integritas jati diri mereka.

\subsubsection{Wacana Belajar Membaca}

Satu kali seorang Ibu Guru kasih anak-anak kelas I dong belajar membaca. Ibu guru tulis bacaan sederhana di papan tulis:

ini budi

ini kakak budi

ini ibu budi

ini ayah budi

Setelah latih anak-anak dong baca sama-sama. Trus ibu guru suruh anak-anak satu per satu maju di depan kelas dan baca.

Begini yang tampil pertama itu Markus. Dia anak asli Papua. Dengan lancar de baca: ini budi/ ini budi pung kakak/ ini budi pung mama/ ini budi pung bapa.

Yang tampil kedua itu Siti yang berasal dari Jawa. Siti membaca: ini budi/ ini kakaknya budi/ ini ibunya budi/ ini ayahnya budi.

Selanjutnya, tampil Ali yang berasal dari Sulawesi. Ali membaca: ini budi mi?/ ini mi? kakak budi/ ini mi? ibu budi/ kalo yang ini mi? bapa?na budi.

Ibu guru su senyum-senyum dan dia minta Tagor yang berasal dari Batak. Anak kecil ini de pu nakal juga... tra putus. Tagor membaca dengan logat yang khas:

ini budi/ ini kakak budi/ ini ibunya budi sekalian bapaknya, bah??

Kelucuan ditimbulkan oleh penafsiran anak-anak yang beragam terhadap teks yang sama. Fenomena ini sering muncul dalam pembelajaran bahasa 
Indonesia di kelas-kelas awal. Para siswa pada umumnya masih memakai bahasa ibunya dalam berkomunikasi di sekolah. Pengalaman ini menunjukkan bahwa pembelajaran bahasa Indonesia di kelas sebaiknya dirancang berdasarkan strategi pemerolehan bahasa pertama (B1) siswa.

Wacana MBMP di atas dapat dipakai sebagai ilustrasi bahwa hal yang wajar jika ketika berbahasa Indonesia terjadi interferensi dari bahasa daerah. Namun, guru perlu melatih anak-anak agar mereka memahami dengan benar tentang bahasa baku dan tidak baku. Secara khusus di Papua, penggunaan bahasa Melayu Papua yang sudah lingua franca ternyata berdampak pada penggunaan bahasa Indonesia pada situasi resmi. Masih banyak guru yang belum mampu menjelaskan kepada siswa mengenai perbedaan bahasa Melayu Papua dan bahasa Indonesia. Hal ini menyebabkan siswa dapat saja menggunakan kedua bahasa tersebut bersama-sama ketika berada pada situasi resmi.

Ilustrasi di atas dapat pula menjadi contoh bahwa sebaiknya guru lebih kreatif menyusun bahan ajar yang sesuai dengan konteks kehidupan siswa seharihari. Misalnya nama budi atau panggilan $i b u$ dan ayah adalah nama dan sapaan yang tidak familiar bagi anak-anak Papua yang berada di daerah-daerah terpencil. Kenyataannya, masih ditemukan guru yang kurang kreatif menggunakan buku paket yang bahan bacaan atau teksnya tidak kontekstual. Diharapkan bacaan sederhana seperti tertera pada Mop di atas sebaiknya dikemas secara kontekstual agar pembelajaran menjadi lebih bermakna bagi siswa.

\subsection{Wacana MBMP yang Berkaitan dengan Pilihan Kata (Diksi)}

\subsubsection{Wacana Langsung Bangkit}

Pada suatu kesempatan, Pak Camat dan isterinya diundang pada suatu acara. Trus begini pembawa acara de minta Pak Camat untuk memberikan sambutan.

Pembawa Acara : Hadirin yang kami hormati, pada kesempatan ini kita akan mendengar sepatah dua patah kata dari Pak Camat selaku pejabat yang sangat peduli dengan pembangunan di kampung ini. Kepada Bapak Camat disilakan.

Pak Camat de kaget tarabae karena pembawa acara tidak bilang dia sebelumnya. Pace trus pikir mo bilang apa di podium nanti. Saat pace sedang pikir-pikir susun kata-kata begini, de pu istri tepuk-tepuk pace pu paha kasih smangat dan berbisik.

Istri Camat: Bapa... tempo sudah. Pembawa acara su panggil Bapa itu? Bapa sudah biasa bicara, to? 
Tara pake lama, Pak Camat langsung menuju mimbar dan mulai kasih sambutan.

Pak Camat : Hadirin yang saya hormati, sebenarnya saya punya 'kemaluan' ini besar sekali. Tapi karena 'dikorek-korek' oleh saya punya istri, maka dia langsung 'bangkit'.

Haaahaahaaeee... tra sadar undangan dong tertawa picah mendengar pernyataan Pak Camat tadi.

Kelucuan tuturan tersebut disebabkan kesalahan penggunaan diksi oleh Pak Camat (PC) secara berlanjut. Pertama, kesilapan makna kata 'malu' dan 'kemaluan' yang oleh PC dianggap dapat dipergunakan secara bergantian atau sama maknanya. Yang dimaksudkan PC sebenarnya malu (kata sifat), tetapi yang terucap justru kemaluan (kata benda) yang mengacu pada kelamin laki-laki. Demikian pula kata 'dikorek-korek' yang sebenarnya disentil atau disentuh serta 'bangkit' yang mengacu pada berani atau percaya diri.

Wacana Mop tersebut dapat digunakan oleh dosen ketika menjelaskan perihal penggunaan diksi dalam berbicara. Insiden PC dalam teks di atas menjadi motivasi bagi mahasiswa agar berupaya meningkatkan kosakata secara memadai sehingga mampu memilih kata yang tepat dalam mengungkapkan maksud atau gagasannya. Selain itu, Mop itu dapat digunakan pula sebagai contoh bahwa setiap pembicara atau orator perlu membuat persiapan yang matang sebelum berbicara di depan publik. Peristiwa itu juga menjadi contoh salah satu metode berpidato, yakni metode tanpa teks.

\subsubsection{Wacana Tumben}

Robeka dia pu teman Lukas sudah tidak masuk sekolah tiga hari. Pas hari keempat begini Lukas de muncul di sekolah dengan muka sedikit pucat. Robeka penasaran, baru dia dekati Lukas dan bertanya.

Robeka : Ee ..., Lukas. Tumben tiga hari ko tidak sekolah, e?

Lukas : Ko benar Beka. Sa ini tumben tiga hari sampe tidak bisa masuk sekolah.

Robeka : Hah?

Kelucuan dalam lelucon di atas tampak pada penggunaan kata 'tumben' yang arti sebenarnya 'tidak biasanya; menyalahi dugaan', tetapi oleh Lukas dianggap bermakna 'sakit perut atau diare'. Lukas mengira Robeka mengetahui bahwa ia tidak masuk sekolah karena sakit diare, sehingga ia berpikir diare sama maknanya dengan 'tumben'. Peristiwa berbahasa di atas disebabkan Lukas 
mencoba menggunakan kata atau istilah yang biasa dipakai oleh teman-temannya yang berbahasa Jawa, bukan dari bahasa Melayu Papua yang selama ini dikenalnya.

Sama halnya dengan wacana MBMP (03), Mop ini dapat digunakan untuk menjelaskan kepada mahasiswa tentang perlunya memilih kata yang tepat untuk mengemukakan suatu gagasan. Jika masih ragu terhadap makna sebuah kata, sebaiknya mencarinya di kamus untuk atau bertanya agar mendapatkan makna yang tepat.

\subsubsection{Wacana Mob Bekas Pacar Presiden}

Anak kecil satu pulang sekolah trus tanya sama de pu mama....

"Mama, tadi di sekolah Ibu Guru bilang Megawati dulu pacar sama SBY..." Trus de pu mama bilang begini “ Eeeee!! Ko anak kecil jangan mo bicara barang begitu, ko masi kecil tidak tau apa-apa ....!!"

Trus anak kecil bilang sama de pu mama begini, "Mama, tidak, tadi Ibu Guru bilang di sekolah itu Megawati tuuu mantan Presiden..."

Lelucon ini diceritakan dengan latar waktu jabatan Presiden RI masih dipegang oleh Susilo Bambang Yudoyono. Pernyataan partisipan (anak) yang keliru dan memancing tawa ini menunjukkan terjadi penyempitan makna kata 'mantan'. Dalam dunia pergaulan anak muda, istilah 'mantan' selalu mengacu pada frase mantan kekasih atau mantan pacar. Misalnya ketika bertemu dengan Linda, Heni berkata, "Linda, tadi saya bertemu mantanmu". Yang dimaksud Heni yaitu mantan kekasih atau mantan pacar Linda. Fenomena inilah yang membuat dalam wacana Mop di atas, anak SD mengartikan 'Megawati mantan Presiden' sebagai Megawati dulunya adalah pacar SBY.

Wacana Mob (05) dapat dijadikan bahan ilustrasi kontekstual bagi calon guru atau guru untuk memperhatikan pola perkembangan bahasa anak ketika mengajarkan suatu konsep. Ketika menggunakan sebuah kata, guru perlu memberikan penegasan yang tepat dan sesuai dengan usia anak sehingga maknanya menjadi lebih jelas. Mop tersebut dapat juga dipakai sebagai ilustrasi bagi kata-kata yang mengalami perluasan dan penyempitan makna. 


\subsubsection{Wacana Pelajaran Berenanglogi}

Ada tete dan cucu. Cucu ini su sarjana, jadi de pulang kampung cari ikan sama tete. Cucu tanya: "Tete, ko tahu Biologi”"?

Tete geleng kepala.

"Baru Sosiologi?" tete geleng kepala lagi.

"Baru Antropologi?" Tete geleng kepala (tapi dalam hati tete su ganas).

Sampe tengah laut, tete tanya ke cucu: "Ko tahu pelajaran Berenanglogi?"

Cucu geleng kepala.

Tete bilang: "Klu ko tratau pelajaran Berenanglogi itu nanti ko Tenggelamlogi trus ko Matiologi... Haaahaahaaeee..."

Unsur kelucuan pada lelucon di atas yaitu sang kakek menggunakan akhiran -logi terhadap kata dasar berenang, tenggelam, dan mati. Padahal akhiran - logi yang berarti ilmu hanya digunakan untuk menandai bidang ilmu tertentu. Misalnya Biologi yang artinya ilmu tentang keadaan dan sifat makhluk hidup atau ilmu hayat.

Wacana Mop tersebut merupakan suatu ilustrasi bahwa seorang penutur hendaknya mengetahui dengan pasti siapa mitra tuturnya. Dengan begitu, ia dapat memilih topik dan bahasa yang sesuai dengan latar belakang mitra tutur. Sebuah komunikasi akan berjalan dengan baik apabila topik yang dibicarakan cocok dengan latar belakang lawan bicara.

Pada Mop (06) terjadi kekurangharmonisan komunikasi antara si cucu dan kakeknya. Si cucu yang telah mengenyam pendidikan tinggi menanyakan sesuatu yang terlalu ilmiah bagi kakek yang pendidikannya mungkin rendah. Kendati demikian, kakek juga beranggapan bahwa ia pun memiliki pengetahuan dan keterampilan hidup yang tidak kalah dengan cucunya, misalnya mampu berenang dan mencari ikan. Itulah sebabnya, ia sengaja menciptakan kata-kata yang lebih 'ilmiah', yakni berenanglogi, tenggelamlogi, dan matiologi untuk mengimbangi cucunya

\subsection{Wacana MBMP yang Berkaitan dengan Konteks Kalimat 2.3.1 Wacana Baca Mantra}

Obed de anak baru masuk kelas tiga SD. Suatu hari de lari-lari menemui Pak Purnomo tetangganya. Obed de minta Pak Pur untuk obati de pu anjing yang sekarat. Pak Pur de senyum-senyum saja mengiyakan. Dong dua langsung menuju rumah Obed.

Lihat Obed pu anjing yang su lemas, Pak Pur yang asli Gunung Kidul Yogya itu, tempelkan de pu telapak tangan di anjing pu jidat itu. Sambil tarik 
napas dalam-dalam, Pak Pur usap kepala anjing itu dan berkata-kata deng bahasa Jawa:

Pak Pur : "Su..., Asu... (njing, anjing), ..... nek kowe arep mati, yo mati o (kalo ko mo mati ya mati sudah)

Trus Pak Pur de lanjut lagi: "Nek arep urip, yo waras o". (kalo ko mo hidup, ya sembuhlah).

Obed yang tra tau bahasa Jawa, de pikir Pak Pur gunakan bahasa Latin. Diam-diam Obed de hafalkan kata-kata Pak Pur tadi, yang Obed kira mantra/doa.

Sudah itu Pak Pur langsung pulang. Beberapa hari kemudian, Obed lari-lari ke rumah Pak Pur dengan maksud mo kasih kabar kalo Obed pu anjing su sembuh.

Sampe di sana ternyata Pak Pur sedang menggigil macam de kena malaria begitu. Obed de terkejut dan langsung menuju Pak Pur pu kamar. Lihat Pak Pur macam mau sekarat, Obed de langsung tempelkan de pu telapak tangan di dahi Pak Pur, sambil baca mantra.

Obed : "Su..., Asu... nek Kowe arep mati, yo mati o ...Nek arep urip, yo waras o...!!!".

Pak Pur de langsung kaget dengar Obed pu kata-kata itu.... de langsung bangun dan tertawa.

Pak Pur : "Wkwkkk....Obed ko kira sa piaraanmu...kah?

Kelucuan dalam peristiwa tutur di atas ditunjukkan oleh tindakan Obed meniru bahasa Pak Purnomo yang tidak dipahaminya. Obed tidak bisa berbahasa Jawa sehingga tidak mengetahui bahwa jampi-jampi digunakan Pak Purnomo dalam bahasa tersebut. Ketika mengobati anjing piaraan Obed, Pak Pur mengatakan "Su..., Asu... Nek kowe arep mati, yo mati o...Nek arep urip, yo waras $o$ ". Karena tidak mengerti, Obed mencoba mantra/doa tersebut untuk mengobati Pak Pur yang sedang sakit. Seandainya Obed mengerti konteks, ia tidak mungkin menggunakan doa itu karena yang sakit adalah manusia, bukan anjing. Wacana Mop ini sangat sarkastis, tetapi memberi pengertian yang baik terhadap kalimat dan konteksnya.

Dalam masyarakat yang multibahasa, kejadian-kejadian ini sering terjadi. Ketidaksamaan kode bahasa membuat para partisipan keliru menafsirkan pesan yang diterima. Ilustrasi ini dapat dipakai untuk menjelaskan pentingnya pemahaman terhadap konteks kalimat dan topik pembicaraan. Ilustrasi ini juga mengingatkan mahasiswa tentang konsep bahasa dan pikiran. Berpikir sebelum berbicara sangat membantu seseorang untuk menata gagasannya secara tepat. Selain itu, ilustrasi ini mengingatkan setiap orang untuk tidak selalu meniru karena bisa saja hal itu berbeda dengan hal yang sebenarnya. 


\subsubsection{Wacana Salah Bulan}

Salah Bulan merupakan contoh peristiwa kesenjangan komunikasi yang terjadi karena para partisipannya berpikir dalam konteks yang berbeda. Hal itu dapat dilihat pada wacana di bawah ini.

Mace Mince de pergi ke PLN untuk bayar iuran listrik. Pas lagi mace de baru hamil 6 bulan. Sampe di tempat kasir, mace Mince antre. Pas de pu giliran begini Pace Amandus yang tugas di loket tanya: "Berapa bulan, Mace?"

Mince de langsung spontan jawab : "Enam bulan, Pace".

Trus Pace Amandus balas: "Enam ratus ribu, Mace". Waktu dengar itu, mace Mince de pu hati ganas sekali karena terlalu mahal, lalu de balas Pace Amandus.

Mace Mince: "Pace, kam stop koropsi sudah. Bulan lalu itu sa cuma bayar seratus ribu. Baru sekarang kenapa bisa jadi enam ratus begini?".

Pace Amandus: "Mace, tadi ko bilang enam bulan, to?"

Mace Mince de pu muka busuk skali. Hehehe tadi dia pikir Pace Amandus tanya de sudah hamil berapa bulan. Mace... mace....dengar baik, kah!!

Makna 'berapa bulan' dalam pikiran Pace Amandus secara lugas mengacu kepada satu referen, yaitu waktu pemakaian daya listrik oleh keluarga Mace Mince. Sebaliknya, dalam pikiran Mace Mince, kata tersebut mengacu pada dua pengertian, yakni banyaknya waktu pemakainan daya listrik dan usia kandungannya. Walaupun tujuan utamanya hendak membayar iuran listrik, Mace Mince secara spontan menyebut angka tiga ketika ditanya oleh Pace Amandus. Penyebabnya karena setiap bertemu dengan kenalannya pasti mereka bertanya tentang usia kandungannya. Wacana ini dapat dipakai untuk menjelaskan tentang bagaimana konteks dan pengetahuan bersama merupakan faktor yang berpengaruh terhadap makna pesan yang diterima.

\subsubsection{Wacana Bagi Habis Aids}

Cerita ini terjadi pada waktu Komisi Pemberantasan Penyakit Aids (KPPA) dong turun ke satu kampung untuk kasih penyuluhan tentang Aids. Ada satu pace yang terkenal di kampung itu paling vokal... de pu nama Thonce.

Pace Thonce de pu smangat saja waktu dengar ada penyuluhan. De su siapsiap hajar tim penyuluh deng satu pertanyaan yang selalu bikin dia penasaran. Tapi karena penyuluhan itu diadakan sore hari, Pace Thonce de pilih pergi ke kebun dulu. Di kebun dia kerja sampai lelah. Jadi, pas ikut penyuluhan di balai desa, pace de tatidor sonoeee... sampe de tra dengar isi penyuluhan. Pas de kaget bangun ini su masuk sesi tanya-jawab. Tra pake tunggu lama, pas tim dong kasih buka sesi tanya-jawab, dia langsung kasih tinggi tangan, jadi dong kasih dia kesempatan pertama. Dengan berapi-api Thonce angkat bicara. 
Thonce : Bapak-bapak, torang di kampung ini sangat setuju dan senang menerima program yang Bapak dong tawarkan. Tapi, selama ini setiap dana yang kam kirim dari kota itu dimakan tikus-tikus kecil jadi de sampe di sini tuu tingkat sedikit saja. Jadi, mewakili sa pu sodara-sodara di kampung ini dengan kerendahan hati sa minta supaya Bapa-bapa bagi HIV Aids itu sampe habisss dan tuntas... supaya kami di kampung bisa merasakan manfaatnya.

Kelucuan wacana MBMP di atas ditunjukkan oleh pemahaman Pace Thonce tentang Aids. Ia mengira Aids itu sejenis program bantuan masyarakat (RESPEK) yang selama ini digelontorkan oleh pemerintah Papua. Selama ini, dana program-program semacam tidak utuh sampai pada masyarakat sehingga kurang dirasakan manfaatnya oleh masyarakat. Oleh sebab itu, Pace Thonce berniat memrotes para penyuluh. Tujuannya agar para pengambil kebijakan dapat memperbaiki kinerja mereka dalam memperjuangkan hak-hak masyarakat kecil.

Mop ini dapat dijadikan ilustrasi kontekstual bahwa pengalaman selalu melandasi konteks berpikir seseorang. Dalam bidang komunikasi bahasa, konsep berpikir Pace Thonce mewarnai kosa kata, kalimat, dan gaya bahasa yang dipakainya. Dalam hal kemahiran berbahasa, Mop tersebut dapat dijadikan ilustrasi tentang faktor-faktor yang mempengaruhi kelancaran berkomunikasi dalam forum atau kegiatan ilmiah. Walaupun sederhana, ilustrasi ini cukup kontekstual untuk menggambarkan perilaku berbahasa yang sebenarnya di masyarakat, khususnya masyarakat kecil di kampung-kampung.

\subsection{Wacana MBMP yang Berkaitan dengan Peribahasa 2.4.1 Wacana Cari di Hutan}

Suatu hari Pak Guru mengajar tentang peribahasa. Setelah menjelaskan pengertian peribahasa, Pak Guru meminta para siswanya untuk melanjutkan sebuah peribahasa yang belum lengkap.

Pak Guru : Anak-anak siapa, yang bisa melanjutkan peribahasa ini?

Tidak ada rotan,

Semua anak mencoba mencari jawabannya, juga Obed. Tiba-tiba Obed angkat Pak Guru : Bagus, Obed. Bagaimana kelanjutan peribahasa itu?

Obed : Tidak ada rotan, cari di hutan.

Pak Guru : e, Obed. Kenapa ko jawab begitu, kah?

Obet : Begini, Pak Guru. Bapa dan bapaade dong biasa cari rotan di hutan, to? 
Wacana Mop di atas merupakan suatu ilustrasi kontekstual yang menunjukkan bahwa setiap anak berpikir sesuai dengan lingkungan terdekatnya. Orang tua Obed adalah petani yang biasa mencari rotan di hutan. Oleh sebab itu, ketika Pak Guru memberikan peribahasa yang masih rumpang Tidak ada rotan,.... dilengkapi Obed dengan ... cari di hutan. Padahal yang dimaksud yaitu Tidak ada rotan, akar pun jadi. Peristiwa bahasa ini dapat digunakan untuk mengimbau guru agar perlu merancang pembelajaran yang melibatkan anak dengan lingkungan agar tercipta pembelajaran yang bermakna. Dari konteks terdekat, guru dalam menggiring siswa untuk berpikir pada konteks yang lebih luas.

\subsubsection{Wacana Makna Peribahasa}

Pada suatu hari Markus pulang sekolah membawa PR bahasa Indonesia. Ia minta tolong bapanya, Pace Philemon, untuk membantu kerjakan PR.

Markus : : Bapa, ibu Guru nih dia kasih tong punya PR susah sampee... dia suruh tong kasih arti peribahasa.

Pace Philemon : Oho... barang apa jadi.. Mo peribahasakah? Pepatakah? Bapa nih yang paling jago sudah waktu sekolah. Kasih kemari ...

Markus : Iyo, Bapa. Ibu guru de tanya; Air beriak tanda tak dalam itu artinya......?

Pace Philemon : (Berpikir sejenak lalu menjawab dengan berapi-api) Anak.... itu ibu guru dia tipu kam. Tempat itu sudah yang dulu Bapa hampir tenggelam di situ.

Kelucuan wacana MBMP (11) disebabkan oleh respon Pace Philemon terhadap pertanyaan anaknya. Ilustrasi ini hampir sama konteksnya dengan wacana MBMP (09). Ternyata benar bahwa pengalaman seseorang berpengaruh terhadap keputusannya menyelesaikan masalah. Pace Philemon yang menurut pengakuannya sendiri ‘jagoan’ dalam peribahasa atau pepatah. Oleh sebab itu, ia memahami bahwa tidak selamanya air beriak tanda tak dalam karena ia sendiri pernah hampir tenggelam di tempat yang 'beriak' tersebut. Fenomena itu dapat ditandai sebagai kearifan lokal karena ada kemungkinan air yang beriak itu dikarenakan oleh arus atau binatang dan bukan karena dangkal. Jawaban yang diberikan pace Philepon pun dapat dijadikan fakta bahwa terdapat beberapa variasi kalimat dalam memberi jawaban terhadap suatu pertanyaan. Misalnya sebuah pertanyaan dapat dijawab dengan pertanyaan pula. 


\subsection{Wacana MBMP yang Berkaitan dengan Gaya Bahasa}

Gaya bahasa merupakan salah satu ciri bahasa sastra. Ciri inilah yang membedakan karya sastra dan karya ilmiah. Kedua wacana MBMP di bawah ini dapat dipakai sebagai ilustrasi kontekstual bagi pembelajaran yang berkaitan dengan ciri-ciri bahasa karya ilmiah dan bahasa karya sastra.

\section{1) Mob Melamar Gadis Papua}

Obet lamar kekasihnya Mince dengan kata-kata mutiara:

Obed : :Sayang tanpa kau, segalanya gelap gulita dan suram, angin melambaikan hujan, lalu muncullah mentari, kau seperti pelangi dan mentari yang hangat untuk saya..."

Mince : "Obed, sebenarnya kau lamar saya atau kasih laporan cuaca....???

\section{2) Mob Dikira Gombal}

Obed mendekati Mina dengan muka gugup. Mina de pu hati bunga-bunga karena memang de naksir berat sama Obed.

Obed : Mina, ko pu bapak nelayan, ya?

Mina : Betul, Obed. Jadi...? ko mo bilang sa tolong menjala ko pu hati, begitu?

Obed : Tra begitu, Mina. Tapi ada nelayan yang meninggal.

Rayuan Obed kepada Mince bersifat metaforis dengan mengandaikan dan membandingkan Mince dengan mentari dan pelangi yang muncul sehabis hujan. Konsep tersebut jika disampaikan dalam karya ilmiah akan lebih lugas dan tidak berbelit-belit. Hal yang sama terdapat pula dalam dalam wacana Mop Dikira Gombal. Berdasarkan gaya berbahasa dan isinya, kedua Mop tersebut diciptakan mengikuti tren humor di media televisi, Gombalin Aku, Dong. Fenomena ini menunjukkan bahwa Mop berkembang sesuai dengan perkembangan zamanehingga tetap kontekstual. Kedua Mop tersebut dapat dipakai dalam pembelajaran sebagai penyegar suasana ketika mahasiswa sudah bosan atau jenuh. Melalui contoh ini mahasiswa pun dapat diberikan kesematan untuk berkreativitas melalui wacana gombal yang relevan dengan topik yang sedang dipelajari.

\section{SIMPULAN}

Pembelajaran kontekstual adalah konsep belajar yang mengaitkan isi pembelajaran dengan konteks kehidupan sehari-hari siswa, baik dari konteks pribadi, sosial, maupun kultural. Mop adalah wacana humor yang disampaikan dalam bahasa Melayu Papua. Isinya mengandung asosiasi makna tertentu yang 
menimbulkan kelucuan dan mengundang tawa dan senyum pendengarnya. Pada umumnya para siswa di Papua sangat familiar dengan Mop. Dengan demikian, Mop dapat dimanfaatkan sebagai ilustrasi kontekstual dalam pembelajaran di Papua.

Hasil kajian menunjukkan bahwa wacana MBMP berkaitan dengan konsep atau prinsip fungsi bahasa, diksi, kalimat, pepatah, dan gaya bahasa. Konsep tersebut jika diajarkan kepada siswa terasa membosankan karena terkesan teoritis. Meskipun disampaikan dalam bahasa Melayu Papua, Mop dapat membantu siswa dalam mempelajari konsep bahasa Indonesia, yakni fungsi bahasa, diksi, kalimat, peribahasa, dan gaya bahasa.

Wacana MBMP yang berkaitan dengan fungsi bahasa dapat dipakai sebagai ilustrasi bahwa dalam peristiwa komunikasi diperlukan kesamaan kode (bahasa). Ketidaksamaan kode bahasa dapat menyebabkan salah tafsir dari para partisipan. Mop digunakan sebagai fakta bahasa bahwa dibutuhkan sebuah bahasa yang dapat mempersatukan masyarakat yang pluralis. ilustrasi tersebut dapat pula menjadi contoh bahwa sebaiknya guru lebih kreatif menyusun bahan ajar yang sesuai dengan konteks kehidupan siswa sehari-hari. Bacaan sederhana apa pun sebaiknya dikemas secara kontekstual agar pembelajaran menjadi lebih bermakna bagi siswa.

Wacana MBMP yang berkaitan dengan pilihan kata dapat dijadikan bahan ilustrasi kontekstual bagi calon guru atau guru untuk memperhatikan pola perkembangan bahasa anak ketika mengajarkan suatu konsep. Mop tersebut dapat juga dipakai sebagai ilustrasi bagi kata-kata yang mengalami perluasan dan penyempitan makna serta perlunya memilih kata yang tepat untuk mengemukakan suatu gagasan.

Wacana MBMP yang berkaitan dengan konteks kalimat dapat dipakai untuk menjelaskan pemahaman konteks kalimat dan topik pembicaraan. Ilustrasi ini juga mengingatkan mahasiswa tentang konsep bahasa dan pikiran. Berpikir sebelum berbicara sangat membantu seseorang untuk menata gagasannya secara tepat. Selain itu, ilustrasi ini mengingatkan setiap orang untuk tidak meniru karena bisa saja hal itu berbeda dengan hal yang sebenarnya. 
Wacana MBMP yang berhubungan dengan peribahasa merupakan suatu ilustrasi bahwa setiap anak berpikir sesuai dengan lingkungan terdekatnya. Oleh sebab itu, guru perlu merancang pembelajaran yang melibatkan anak dengan lingkungan agar tercipta pembelajaran yang bermakna. Dari konteks terdekat, guru dalam menggiring siswa untuk berpikir pada konteks yang lebih luas.

Berdasarkan simpulan di atas, disarankan kepada para guru dan dosen agar dapat memanfaatkan wacana MBMP sebagai ilustrasi pembelajaran. Pembelajaran yang menarik dan menantang sebenarnya tidak membawa siswa keluar dari konteks budayanya, tetapi membimbing siswa memahami suatu konsep melalui konteks terdekatnya. Oleh sebab itu, para pengajar dapat berkreasi menghimpun atau mencipta wacana Mop yang relevan dengan isi pembelajaran sehingga proses belajar-mengajar menjadi lebih bermakna dan menarik.

\section{DAFTAR RUJUKAN}

Cook, Guy. 1994. Discourse and Literature :The Interplay of Form and Mind. New York: Oxford University Press.

Danandjaya, J. 2002. Folklor Indonesia: Imu Gosip, Dongeng, dan Lain-lain. Jakarta: Pustaka Utama Grafiti.

Eriyanto. 2011. Analisis Isi: Pengantar Metodologi untuk Penelitian Ilmu Komunikasi dan Ilmu-ilmu Sosial Lainnya. Jakarta: Kencana.

Iwong, Ch. H. 2012. Perubahan Makna dalam Wacana Mob Bahasa Melayu Papua: Kajian Semantik. Thesis. Malang: Universitas Negeri Malang.

Kutha Ratna, N. 2010. Metodologi Penelitian: Kajian Budaya dan Ilmu Sosial Humaniora pada Umumnya. Yogyakarta: Pustaka Pelajar.

Miles, Mathew B. dan A. Michael Huberman. 1992. Analisis Data Kualitatif. Jakarta: Universitas Indonesia.

Rahmanadji, D. 2007. Sejarah, Teori, Jenis, dan Fungsi Humor. Malang: Jurnal Bahasa dan Seni, Tahun 35 Nomor 2, Agustus 2007.

Warami, H. 2009. Mob Melayu Papua. Manokwari: Unipa Press. 